\title{
CUTTING OF WOODY SHRUBS AT MELIORATION OBJECTS BY A MULTI-ROTOR MOWER WITH TRAPEZOIDAL KNIVES
}

\author{
Jan Radosław Kamiński ${ }^{\text {a* }}$, Maciej Kuboń ${ }^{b}$, Evgenij Ivanovič Mażugin ${ }^{c}$, \\ Sergej Grigorevič Rubec ${ }^{c}$ \\ ${ }^{\text {a }}$ Department of Agricultural and Forest Machinery, Warsaw University of Life Sciences - SGGW \\ ${ }^{\mathrm{b}}$ Institute of Agricultural Engineering and Informatics, University of Agriculture in Krakow \\ c Belorussian Agricultural Academy, Gorki, Mogilev Region, Belarus \\ "Corresponding author: e-mail: jan_kaminski@sggw.waw.pl
}

ARTICLE INFO

Article history:

Received: January 2016

Received in the revised form:

March 2016

Accepted: May 2016

Key words:

multi-rotor mower

woody shrubs,

trapezoidal knives,

melioration objects,

cutting,

efficiency

\begin{abstract}
The object of the research is a technological process and technical means of cutting woody shrubs at melioration objects. The subject of the research consists of regularities and methods of execution of the process of cutting woody shrubs at melioration objects by a multirotor mower with trapezoidal knives. The aim of the research is to increase efficiency of cutting shrubs at melioration objects by applying a multi-rotor mower with trapezoidal knives. We have obtained analytical dependences in order to determine the angle of diversion of a knife from the radial position during contact with the stem, and to calculate the reaction in the joint "knife-fixing bolt" depending on the parameters of a knife and rotor, and the distance from the centre of the knife fixing bolt to the point of contact of a knife and stem, which provides minimal impact load on the knife fixing bolt during cutting woody shrubs. We have also developed a mathematical model of the process of cutting shrubs by a multi-rotor mover with trapezoidal knives, and methods of determination of the main parameters and regimes of work of the mower cutting apparatus for cutting shrubs at melioration objects, which contain a monogram, based on the use of theoretical-experimental dependences.
\end{abstract}

\section{Введение}

Важнейшей составной частью земель сельскохозяйственного назначения являются мелиорированные земли. Площадь земель, осушаемых закрытым дренажем, в Республике Беларусь составляет 2231,9 тыс. га. К числу основных элементов, предопределяющих функционирование мелиоративной системы, относятся каналы. Общая протяженность каналов и водоприемников в Республике Беларусь составляет около 170 тыс. км (Титов и Гуцанович, 2009). Одним из основных процессов, нарушающих работоспособность мелиоративных каналов, является их зарастание травяной и древесно-кустарниковой растительностью. Скашивание и удаление травянистой и древесно-кустарниковой растительности с откосов, берм каналов и дна является одной из основных операций по уходу за мелиоративными системами. 
Операция окашивания каналов выполняется сегодня разнообразными машинами, как зарубежных, так и отечественных производителей. Основной объем работ по скашиванию растительности выполняется многороторными косилками с шарнирно закреплёнными ножами. На выполнение этой операции затрачивается около $25 \%$ от общих затрат на проведение ремонтно-эксплуатационных работ (Кондратьев, 2007).

Анализ существующих технических средств, применяющихся при скашивании древесно-кустарниковой растительности на мелиоративных объектах, показывает, что наиболее совершенными и надежными являются многороторные косилки с шарнирно закрепленными ножами, однако и они не в состоянии достаточно эффективно окашивать площади мелиоративных объектов, особенно при наличии на них древесно-кустарниковой растительности. На основании изложенного можно утверждать, что повышение эффективности скашивания растительности на мелиоративных объектах является актуальной проблемой.

Целью исследований является повышение эффективности скашивания растительности на мелиоративных объектах применением многороторной косилки с трапециевидными ножами.

Объектом исследования является технологический процесс и технические средства для скашивания древесно-кустарниковой растительности на мелиоративных объектах.

Предметом исследования являются закономерности и методы осуществления процесса скашивания древесно-кустарниковой растительности на мелиоративных объектах многороторной косилкой с трапециевидными ножами.

\section{Анализ источников}

Несмотря на достаточно продолжительный опыт эксплуатации роторных режущих аппаратов, их режущие элементы имеют большое разнообразие форм и конструкций (Корнилович, 2007; Мажугин, 2010), что говорит о продолжающемся поиске наиболее рациональной конструкции. Однако они не в полной мере учитывают специфические условия работы, описанные выше. Для обеспечения качественного срезания как тонкостебельной травянистой, так и кустарниковой растительности, нами предложена усовершенствованная конструкция ножей роторной косилки (Шаршунов и др., 2009, Мажугин и Рубец, 2011), схема которых представлена на рисунке 1.

Конструкция ножа представляет собой вытянутую стальную пластину 1 с отверстием для болта 2 для крепления к ротору на одном из ее концов и имеющую заостренные боковые режущие кромки 3, которые расположены радиально, кроме того нож выполнен расширяющимся к периферии, а внешняя торцовая кромка 4 изготовлена по дуге окружности с центром, совпадающим с центром ротора.

Нож такой конструкции по сравнению с ножом прямоугольной формы имеет бо́льшую массу, более удаленный от центра болта центр масс, что позволяет передать более высокую энергию воздействия ножей на стебли растительности и ожидаемую повышенную эффективность работы за счет большей кинетической энергии ножа и стабилизации его положения во время срезания растительности. 

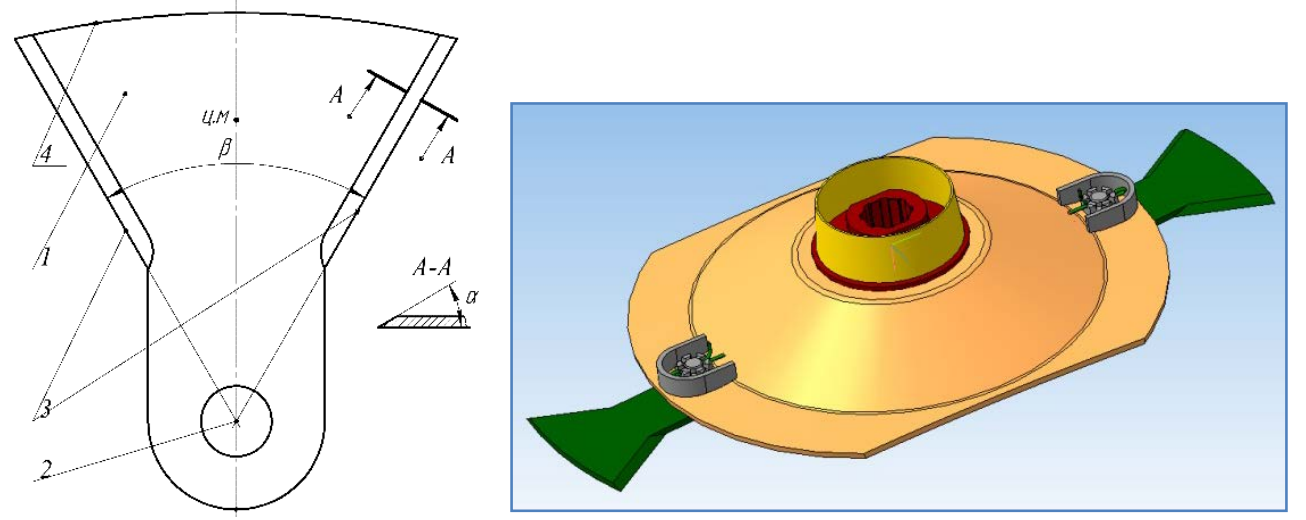

1 - пластина; 2 - отверстие для болта; 3 - режущие кромки; 4 - торцовая кромка ножа

Рисунок 1. Конструкция трапещчевидного ножа роторной косилки

Наиболее полно рабочий процесс роторных режущих аппаратов при срезании травянистой растительности рассмотрен в работах (Резник, 1975; Мартынов, 2009; Новиков, 1957; Фомин, 1963). Но авторы этих работ не рассматривают вопрос о влиянии геометрических параметров ножей и режимов работы режущего аппарата на энергетические показатели косилки при срезании кустарниковой растительности, что делает его актуальным для рассмотрения.

\section{Методы исследования}

Для теоретического анализа была разработана расчетная схема, приведенная на рисунке 2. На схеме контурной линией изображен нож с углом расхождения режущих кромок $\beta$. На него наложен чертеж ножа прямоугольной формы (угол расхождения режущих кромок $\beta=0^{\circ}$, штриховой контур DILE) и нож с отрицательным углом $\beta$, т.е. с сужающимися режущими кромками (штриховой контур DFPGE).

Значимыми характеристиками ножа, зависящими от угла расхождения режущих кромок и влияющими на эффективность срезания грубостебельной и древеснокустарниковой растительности, являются координата центра масс ножа $y_{u . м}$, величина окружной скорости центра масс $v_{u, \mu}$, импульс силы ножа $p_{u, \mu}$, момент инерции ножа $I_{u н}$, и величина кинетической энергии ножа $E_{\kappa}$.

На схеме приняты следующие обозначения: $O_{1} O_{2}$ - расстояние от центра ротора до оси крепления ножа; $O_{1} A-$ расстояние от оси крепления ножа до периферийного конца режущей кромки; $R$ - радиус ротора и дуги, образующей внешнюю торцовую кромку; $D E=F G$ - ширина прямоугольного участка ножа; $F K=G M$ длина прямоугольного участка ножа; $N P$ - длина ножа; $h_{n}$ - толщина ножа; $r_{1}$ - радиус отверстия для болта; $r_{2}-$ внешний радиус полукольцевой части ножа. Значения $D E$, $h_{h}, r_{1}$ и $r_{2}$ определяются прочностными расчетами, а $R$ и $O O_{1}-$ кинематическими расчетами режущего аппарата на основании его параметров. 


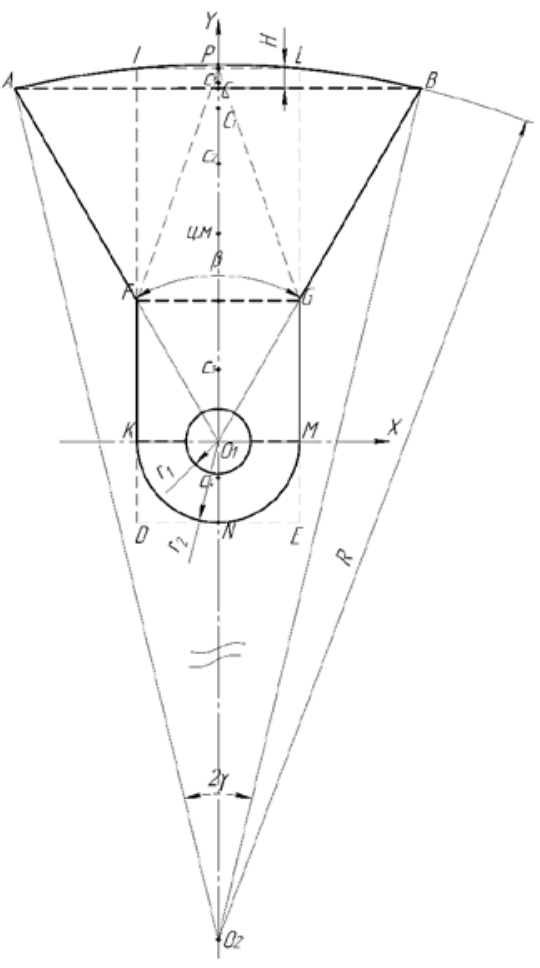

Рисунок 2. Расчетная схема к анализу угла расхождения режущих кромок ножей

Представим нож, состоящим из следующих простых геометрических фигур: сегмента $A B P$, трапеции $A B G F$, прямоугольника FGMK (площадью половины отверстия для болта крепления пренебрегаем, так как ее величина не оказывает существенного влияния на точность расчетов), полукольца, расположенного под осью $X$.

Пренебрегая режущими кромками, вертикальную координату центра масс ножа можно определить по следующей зависимости:

$$
y_{u . M}=\frac{S_{1} y_{c 1}+S_{2} y_{c 2}+S_{3} y_{c 3}+S_{4} y_{c 4}}{S_{1}+S_{2}+S_{3}+S_{4}},
$$

где:

$S_{1}, S_{2}, S_{3}, S_{4}$ - площадь фигур, составляющих нож:

$S_{1}$ - площадь сегмента $A B P$,

$S_{2}$ - площадь трапеции $A B G F$,

$S_{3}$ - площадь прямоугольника FGMK,

$\mathrm{S}_{4}$ - площадь полукольца,

$y_{c 1}, y_{c 2}, y_{c 3}, y_{c 4}-$ расстояние от оси крепления ножа до центра масс каждой из фигур соответственно. 
Cutting of woody...

При встрече ножа с растительностью он поворачивается вокруг точки $O_{1}$. Момент инерции ножа относительно этой точки, определим по теореме Штейнера:

$$
I_{u H_{O 1}}=I_{u H_{\psi \cdot M}}+m_{H} \cdot y_{u \cdot M}^{2},
$$

где:

$I_{\text {ин ц.м }}$ - момент инерции ножа относительно центра масс,

$m_{н} \quad$ - масса ножа.

Окружную скорость центра масс ножа определим по формуле:

$$
v_{u \cdot M}=\omega\left(O_{1} O_{2}+y_{u \cdot M}\right),
$$

где:

$\omega-$ - угловая скорость ротора.

Импульс силы $p_{\psi, \mu}$ ножа будет равен:

$$
p_{u \cdot M}=m_{H} \cdot v_{u \cdot M} .
$$

Величину кинетической энергии ножа $E_{\kappa}$ определим по следующей зависимости:

$$
E_{\kappa}=\frac{m_{u} v_{u \cdot M}^{2}}{2}+\frac{I_{u u} \omega^{2}}{2} .
$$

Предложенная методика (Шаршунов и др., 2013а) используется для расчета координаты центра масс ножа, момента инерции ножа, массы ножа, окружной скорости центра масс ножа, импульса силы и кинетической энергии ножа в зависимости от угла расхождения его режущих кромок.

Используя полученную методику, рассчитываем координату центра масс ножа, величину окружной скорости центра масс, импульс силы ножа, момент инерции ножа относительно оси крепления ножа, а также величину кинетической энергии для ножа с сужающимися режущими кромками, серийного ножа прямоугольной формы, а также ножа с углом расхождения режущих кромок $30^{\circ}, 40^{\circ}, 50^{\circ}, 70^{\circ}, 80^{\circ}, 90^{\circ}$ и $100^{\circ}$ и путём сравнительного анализа определим рациональное значение угла расхождения режущих кромок. Значения угла расхождения менее $30^{\circ}$ не рассматриваем, так как в этом случае нож имеет форму близкую к прямоугольной. В графическом виде результаты расчётов приведены на рисунке 3.

Анализируя данные зависимости, можно сделать следующие выводы.

По сравнению со стандартным ножом с параллельными режущими кромками предлагаемый нами нож имеет увеличенную окружную скорость центра масс на $4 \%$ при угле $60^{\circ}$, масса увеличивается на $13 \%$, величина координаты центра масс на $10 \%$, вследствие чего момент инерции возрастает на $50 \%$, импульс силы и кинетическая энергия ножа на 28\%. Это позволяет ожидать повышение эффективности работы ножей.

С увеличением угла расхождения режущих кромок, величина координаты центра масс увеличивается и достигает максимального значения при угле $65^{\circ}$, после чего наблюдается снижение. Аналогично выглядит зависимость окружной скорости. Момент инерции ножа достигает максимального значения при угле расхождения 
режущих кромок $70^{\circ}$, при этом величина импульса ножа и его кинетической энергии возрастает пропорционально увеличению угла расхождения режущих кромок, достигая максимальных значений при $\beta=90^{\circ}$ и $87^{\circ}$ соответственно.

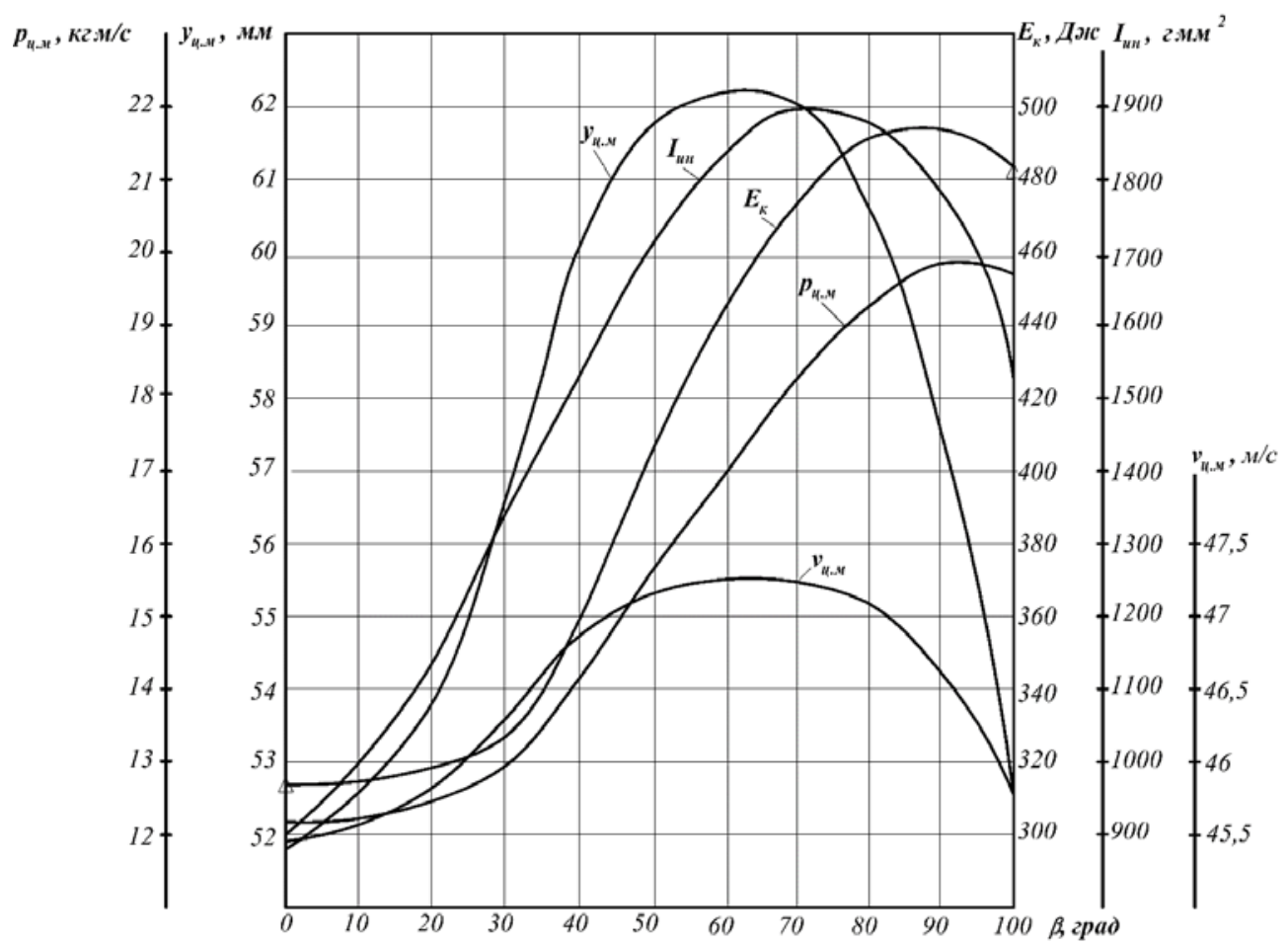

Рисунок 3. Графические зависимости координаты ияентра масс, окружной скорости центра масс, импульса силь, момента инерции и кинетической энергии ножа от угла расхождения режущцих кромок

Однако увеличение угла расхождения режущих кромок до 85-90 приводит увеличению массы ножа на 30-35\%, при увеличении импульса силы и кинетической энергии ножа на 7\%. Кроме того, при углах расхождения более либо равных $85^{\circ}$ ножи не смогут повернуться на достаточный угол, для осуществления срезания. Также по кинематическим соотношениям это приводит к увеличению перекрытия ножей, в результате чего ножи могут соприкасаться. Таким образом рациональное значение угла расхождения режущих кромок ножа находится в интервале $65-70^{\circ}$.

Исследование рассчитанных выше характеристик ножей также было проведено при помощи прикладного пакета программы КОМПАC-3D V15. Для этого были построены трехмерные модели рассматриваемых ножей. Это позволило учесть наличие режущих кромок. В выше приведенных расчетах наличие режущих кромок 
не учитывалось. Построение трехмерных моделей проводили, используя исходные данные к расчетной схеме.

Для примера на рисунке 4 изображена трехмерная модель ножа с углом расхождения режущих кромок $60^{\circ}$ и углом заострения режущих кромок $20^{\circ}$. Используя команду «вычисление массо-центровых характеристик», получили значения массы ножа $\left(m_{H}=347,4\right.$ г), координаты центра масс ножа $\left(y_{u, u}=62,67\right.$ мм $)$ и момента инерции $\left(I_{u h}=1817,89 \Gamma^{\cdot} \mathrm{Mm}^{2}\right)$, которые весьма близки к значениям, полученным расчетным методом. Они равнялись 358,1 г, 62,24 мм и 1825,1 г мм 2 соответственно, это показывает, что погрешность вычислений не превышает $3 \%$.

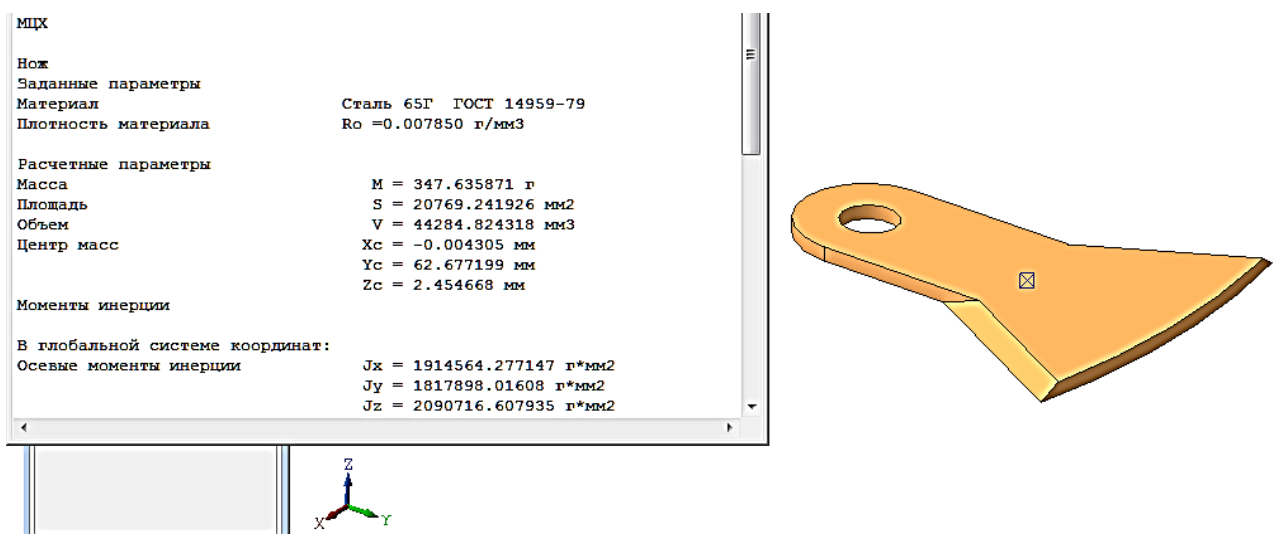

Рисунок 4. Расчетные параметры ножа, полученные при помощи прикладного пакета программы КОМПАС-3D V15

Анализ усилий, действующих на режущую кромку в процессе скашивания, когда она рассматривается в виде клина, внедряемого в растительный элемент, позволил получить уравнение для определения сопротивления срезанию:

$$
F=F_{p}+F_{m p s}\left(\sin \alpha_{1}+f \cos \alpha_{1}\right)+F_{m p н}\left(\sin \alpha_{2}+f \cos \alpha_{2}\right),
$$

где:

$F_{p} \quad$ - сила, действующая на режущую лобовую кромку ножа, $\mathrm{H}$

$F_{m p в}$ и $F_{m p н}-$ силы трения материала о верхнюю и нижнюю фаски режущей кромки соответственно, $\mathrm{H}$

$\alpha_{1}$ и $\alpha_{2}-$ углы, образуемые верхней и нижней фасками режущей кромки ножа с плоскостью его перемещения,

$f$ - коэффициент трения растительности о сталь.

Оценка влияния сопротивления срезанию на вариант заострения режущей кромки позволяет сделать вывод, что при верхнем варианте заострения режущей кромки сопротивление срезанию будет меньше по сравнению с нижним вариантом. 
В результате анализа взаимодействия ножей со скашиваемой растительностью получена зависимость, позволяющая определить минимально необходимую скорость для горизонтального срезания растительности, которая показывает, что величина скорости резания в первую очередь зависит от физико-механических свойств и линейных размеров срезаемой растительности, а также высоты срезания режущего аппарата. При работе на мелиоративных объектах скашивание зачастую происходит на наклонных поверхностях. В этом случае расчетная схема действующих усилий будет иметь следующий вид (рис. 5) и уравнение для определения минимально необходимой скорости резания:

$$
v_{p} \geq \frac{-\frac{W_{u 3}}{\left(x_{s}-H_{c p}\right) \cos \lambda}+\sqrt{\left(\frac{W_{u 3}}{\left(x_{s}-H_{c p}\right) \cos \lambda}\right)^{2}+\frac{12 \Delta t E I_{o} P_{c p}}{\left(H_{c p} \cos \lambda\right)^{3}}}}{\frac{6 \Delta t E I_{o}}{\left(H_{c p} \cos \lambda\right)^{3}}},
$$

где:
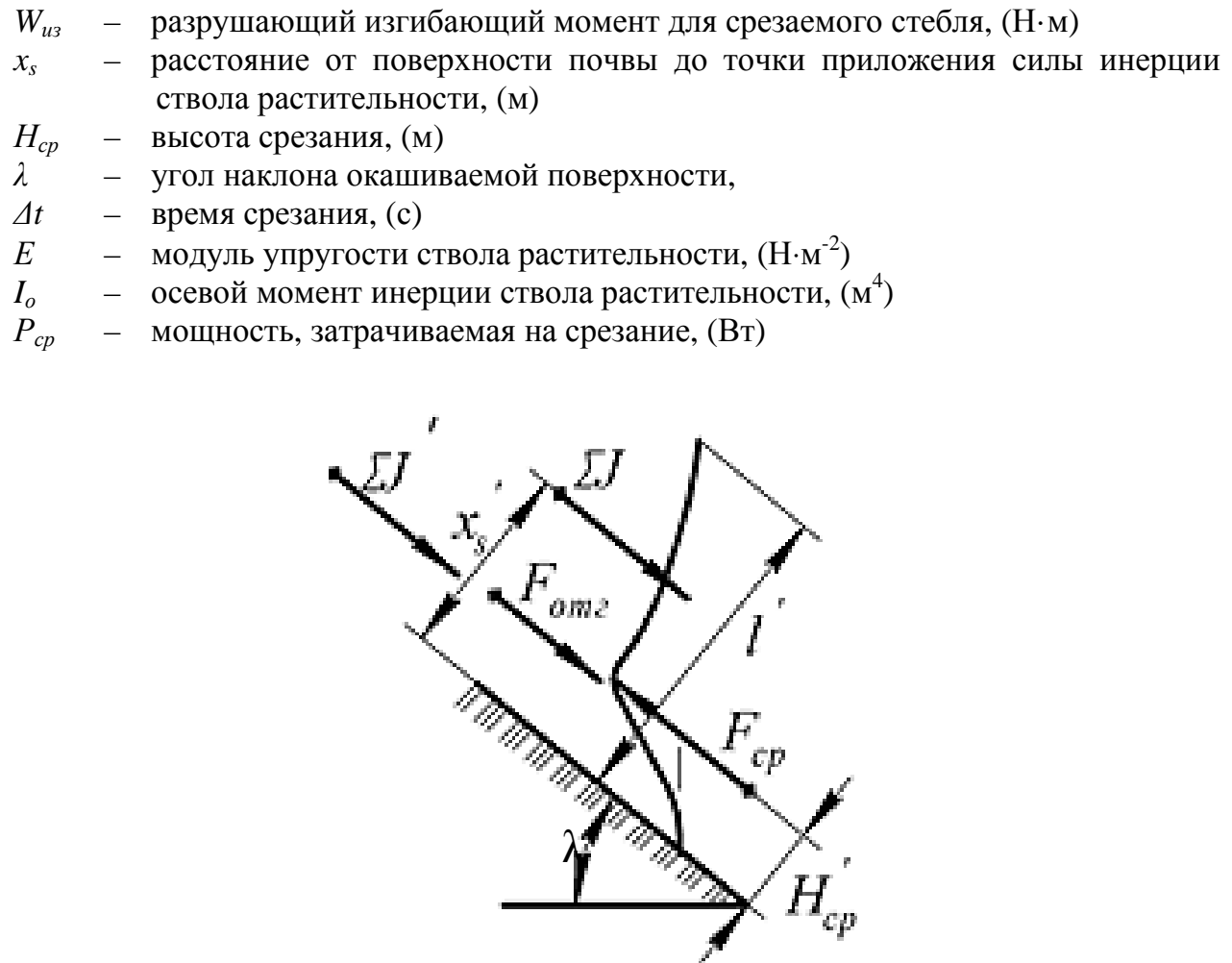

$\Sigma J$ - сила инерции ствола, препятствующая его отклонению, $\mathrm{H} ; \Sigma \vec{J}$ - часть силы инерции, необходимой для изгиба ствола в месте удара, $\mathrm{H} ; F_{c p}$, - усилие, необходимое для срезания ствола, $\mathrm{H}$.

Рисунок 5. Схема действия усилий на ствол растительности во время удара при срезании на наклонной поверхности 
Одним из наиболее часто встречающихся отказов режущих аппаратов роторных косилок является деформация шарнирного сопряжения «нож - болт крепления». В результате анализа расчетной схемы (рисунок 6), учитывающей все значимые усилия, действующие на нож при срезании растительности, получено уравнение для определения реакции $R_{u}$ в шарнирном соединении:

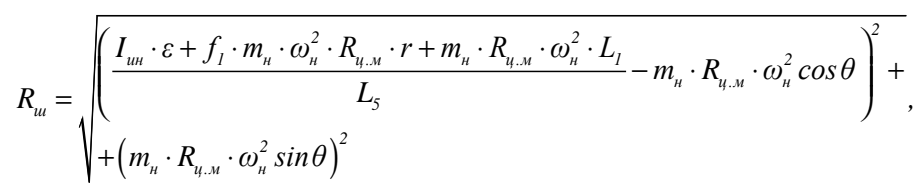

где:

$$
\begin{array}{ll}
I_{u н} & - \text { момент инерции ножа, }\left(\text { кг· }{ }^{2}\right) \\
\varepsilon & - \text { угловое ускорение ножа, }\left(\text { рад·с }{ }^{-2}\right) \\
f_{1} & - \text { коэффициент трения в шарнирном соединении, } \\
m_{H} & - \text { масса ножа, (кг) } \\
\omega_{H} & \left.- \text { угловая скорость ротора, (рад· }{ }^{-1}\right) \\
r & - \text { радиус отверстия в ноже под болт крепления ножа к ротору, (м) } \\
\theta & - \text { угол отклонения ножа от радиального положения, (град) }
\end{array}
$$

Анализ влияния усилий, действующих на нож в процессе срезания, позволил получить зависимость для определения угла отклонения ножа от радиального положения:

$$
\theta=\arcsin \frac{F_{p} \cdot L_{5}-I_{u H} \cdot \varepsilon}{m_{H} \cdot \omega_{H}^{2} \cdot r_{u, M}\left(f_{1} \cdot r+R_{l}\right)} .
$$

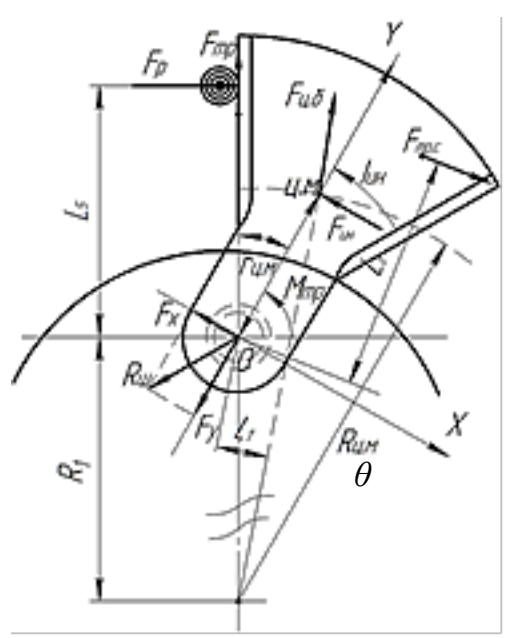

Рисунок 6. Схема взаимодействия растительности
$F_{\mathrm{p}},-$ сила сопротивления срезанию, действующая на режущую кромку ножа со стороны стебля кустарника, $\mathrm{H} ; F_{\text {тр }}, F_{\text {тр.с }}-$ соответственно силы трения режущей кромки о кустарниковую растительность и трения плоскости ножа о стерню, $H$; $F_{\text {ц.б, }} F_{\text {ин }}-$ соответственно центробежная сила и сила инерции, $\mathrm{H} ; M_{\text {тр }}$,-момент сил трения в шарнире Н·м. $I_{\text {ин }}-$ момент инерции, препятствующий повороту ножа, кг· $\mathrm{M}^{2}$

трапециевидного ножа со стеблем 
Конфигурация трапециевидных ножей должна обеспечивать снижение ударной нагрузки на болт крепления. Теоретически обеспечивается минимальная ударная нагрузка на болт крепления ножа при выполнении условия:

$$
y_{y \partial}=\frac{I_{u H}}{r_{u \cdot M} \cdot m_{H}},
$$

где:

$$
\begin{gathered}
y_{y d} \quad-\quad \text { расстояние от центра болта крепления до точки контакта ножа со стеблем } \\
\quad \text { растительности, (м) } \\
r_{u, м} \quad-\quad \text { расстояние от оси крепления ножа до центра масс ножа, (м) }
\end{gathered}
$$

Результаты расчета параметра $y_{y д}$ для ножа прямоугольной формы, а также ножей с углом расхождения режущих кромок $30,40,50,70,80,90$ и $100^{\circ}$ в зависимости от угла расхождения режущих кромок $\beta$ представлены графически на рисунке 7.

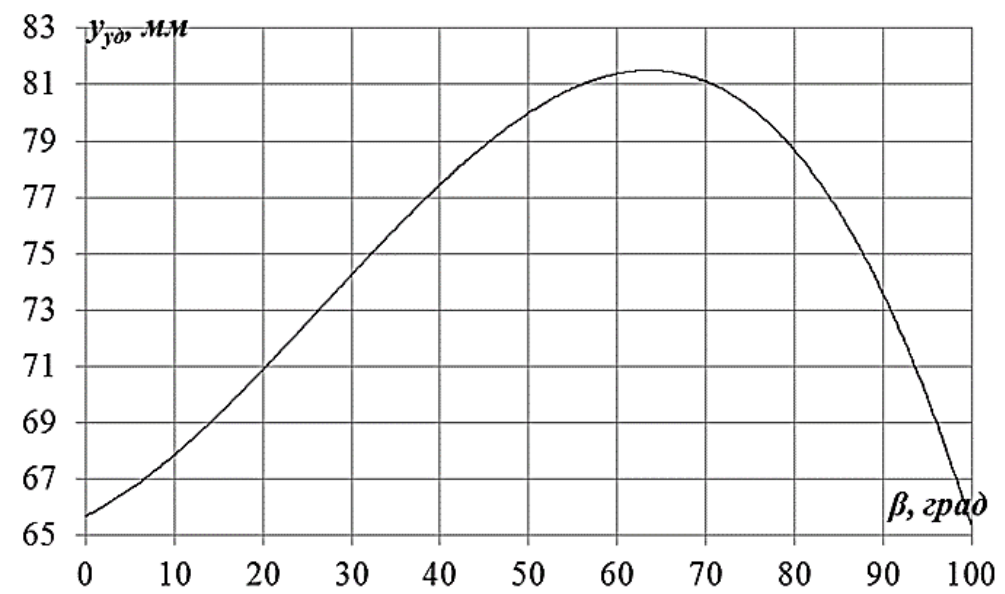

Рисунок 7. Зависимость расстояния приложения ударной нагрузки от угла расхождения режущих кромок ножа

Анализ представленной зависимости показывает, что при угле расхождения режущих кромок от 60 до $70^{\circ}$ разрушающая реакция, действующая на болты крепления ножей во время скашивания, при ударе ножа по стеблю растительности будет минимальной.

Таким образом, для известных параметров ротора, его ножа и окружной скорости можно получить формулу для расчета скорости рабочего передвижения косилки, при которой будет обеспечена наименьшая нагрузка на болт и соответственно наибольшая эффективность срезания растительности: 
Cutting of woody...

$$
v_{n}=\frac{2\left(L_{u}-y_{y d}\right) v_{p} \cdot z_{u}}{\pi \cdot D_{p}},
$$

где:

$L_{н} \quad$ - расстояние от центра болта ножа до внешнего края ножа, (м)

$v_{p} \quad-$ окружная скорость ножей, $\left(\right.$ м. $\left.{ }^{-1}\right)$

$Z_{H} \quad$ - число ножей на каждом роторе,

$D_{p} \quad$ - диаметр ротора по концам ножей, (м)

Глубокое, всестороннее исследование технологического процесса срезания кустарниковой растительности предлагаемым режущим ножом предусматривает учет всех факторов, оказывающих влияние на протекание и конечные результаты изучаемого процесса. При этом все факторы должны быть управляемыми и контролируемыми. Поэтому для проведения лабораторных исследований были приняты следующие конструктивные, технологические и кинематические параметры рабочих органов, выбранные на основании априорной информации: угол заточки режущих кромок ножей $\alpha$ на (рис. 1); угол расхождения режущих кромок ножей $\beta$ на (рис. 1); поступательная скорость перемещения режущего аппарата и частота вращения ротора.

Для проведения исследований была изготовлена лабораторная установка (рис. 8), и ножи предлагаемой конструкции, что позволяло в необходимых пределах изменять выбранные факторы.

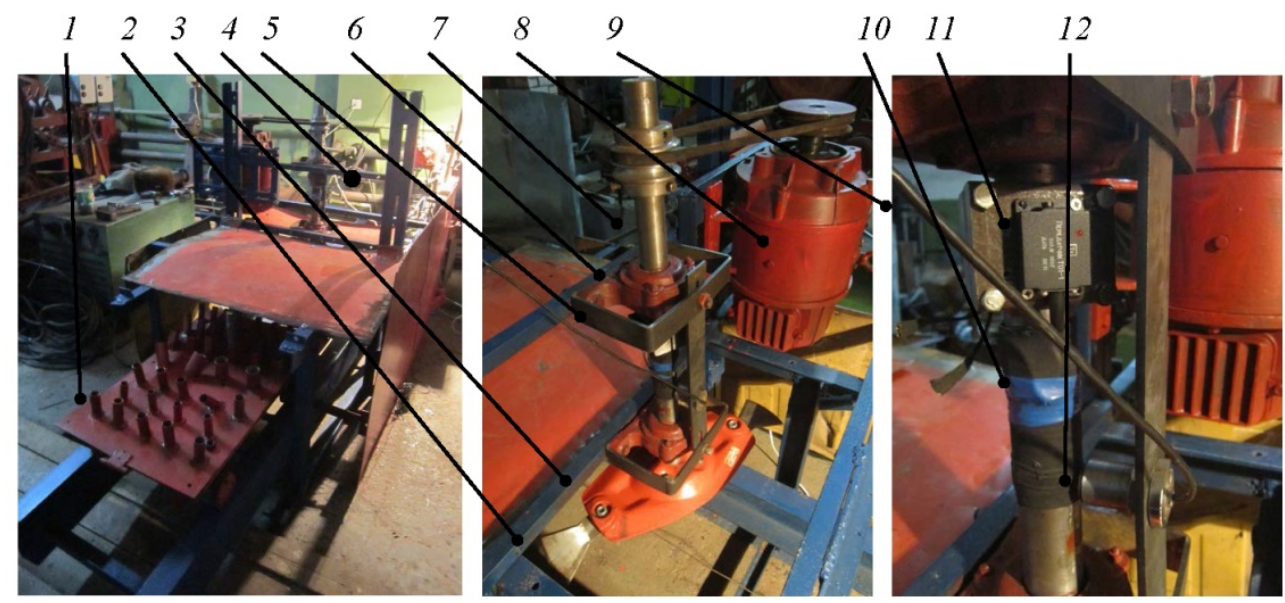

1 - тележка; 2 - ножи; 3 - ротор; 4 - станина; 5 - рамка; 6 - подшипниковые опоры; 7 - вал; 8 электродвигатель; 9 - кабель; 10 - тензорезисторы; 11 - передатчик; 12 - приемник

Рисунок 8. Лабораторная установка 
Установка состоит из станины 4, на которой крепятся подшипниковые опоры 6. В опорах посажен вал 7, на нижний конец вала при помощи шпоночного соединения посажен ротор (диск) 3 с шарнирно закрепленными двумя режущими ножами 2. В исследованиях использовался ротор, устанавливаемый на широко применяющихся роторных косилках КРН-2,1Б, КДН-210, АС-1.

К станине присоединяется электродвигатель 8. На выходном конце вала электродвигателя закреплен ведущий шкив ременной передачи, который при помощи клинового ремня приводит во вращение ведомый шкив ременной передачи и вал 7. Для исследований использовался электродвигатель постоянного тока марки 4ПНМ112М с номинальной частотой вращения $n_{\mathrm{H}}=2800$ мин $^{-1}$ и номинальной мощностью 3,55 кВт. Изменение частоты вращения вала 7 производилось при помощи включенных в электрическую цепь привода электродвигателя 8 выпрямителя и линейного автотрансформатора.

На станине также установлена тележка 1, перемещаемая приводом по направляющим станины. На платформе тележки 1 имеются гнезда для крепления исследуемых образцов растительности, причем гнезда имеют разные диаметры (от 10 до 50 мм) и разный угол наклона к вертикали (от 0 до 45ㅇ), что при необходимости позволяет имитировать срезание растений, стволы которых наклонены к поверхности почвы. В данных исследованиях плоскость вращения ножей располагалась на высоте 60 мм над верхним краем гнезда крепления образца, что соответствует высоте срезания выпускающихся серийно многороторных косилок.

Режущие ножи были изготовлены из стали 65Г с углом заточки режущих кромок 20, 25, 30, 35 и 40 высотой 5 мм и длиной 125 мм. Ножи были выполнены стандартной прямоугольной формы, что соответствовало углу расхождения режущих кромок $0^{\circ}$ и ножи с углами расхождения режущих кромок 45, 60 и $75^{\circ}$

Для оценки влияния выбранных факторов на энергетические затраты при срезании, в качестве параметра оптимизации, по которому оценивался процесс срезания кустарниковой растительности, производили замер величины крутящего момента на валу 7, возникающего от силы сопротивления срезанию кустарниковой растительности при помощи оборудования для тензометрирования. Эта величина позволяет путем несложных вычислений перейти к таким показателям как мощность, затрачиваемая на срезание, и усилие сопротивления срезанию. Импульс, возникающий при срезании образца поступает через передатчик 11 на тензорезисторы 10, наклеенные на вал 7, откуда снимается приемником 12, находящимся на рамке 5, и по кабелю 9 поступает на многоканальный измерительный усилитель Spider 8, подсоединенный к ноутбуку с установленным специализированным программным обеспечением. Результат выводился на дисплей ноутбука в виде диаграммы.

По результатам проведенных поисковых экспериментов были установлены следующие рациональные интервалы варьирования факторов при срезании кустарниковой растительности: угол заточки режущих кромок ножей $-20-40^{\circ}$, угол расхождения режущих кромок ножей - 0-75을 поступательная скорость перемещения режущего аппарата $-0,5-1 \mathrm{M} \cdot \mathrm{c}^{-1}$, частота вращения ротора с ножами -1000 2000 мин $^{-1}$

Для того чтобы определить оптимальное сочетание выделенных факторов, были проведены эксперименты согласно матрице планирования полного факторного 
эксперимента $2^{3}$. После проведения экспериментов проводилось крутое восхождение по поверхности отклика. Полученная линейная модель неадекватно описывала процесс срезания, поэтому далее проводили крутое восхождение по поверхности отклика и описание почти стационарной области уравнением второго порядка, которое учитывает кривизну поверхности отклика.

\section{Результаты}

Обработка экспериментальных данных проводилась на компьютере при помощи пакета прикладных программ Microsoft Office Excel. В результате обработки экспериментальных данных были получены уравнения регрессии в кодированной и натуральной формах. Проведенный анализ показал, что полученная математическая модель адекватно описывает поверхность отклика.

В кодированной форме уравнение имеет вид:

$$
\begin{aligned}
& y=0,134+0,039 x_{1}-0,026 x_{2}-0,012 x_{4}-0,07 x_{12}+0,003 x_{24}- \\
& -0,006 x_{14}+0,021 x_{1}^{2}+0,019 x_{2}^{2}+0,025 x_{4}^{2} .
\end{aligned}
$$

Для интерпретации результатов уравнения (12) и возможности его использования в качестве расчетной формулы было произведено его раскодирование по общепринятой методике (Мельников и др., 1976; Бохан и др., 1986). В результате получили уравнение (13) в натуральной форме следующего вида:

$T=7,242-0,0057 \alpha-0,1094 \beta-0,0083 n-0,00007 \alpha \cdot \beta+0,000003 \beta \cdot n-$

$-0,000011 \alpha \cdot n+0,00073 \alpha^{2}+0,00005 \beta^{2}+0,000003 n^{2}$.

В результате канонического преобразования математической модели определили вид поверхности отклика. Поверхность отклика представляет собой трехмерный параболоид. Анализ области оптимума полученной математической модели проводили методом двумерных сечений при помощи прикладной программы «Mathcad 13» (рис. 9).

Анализируя фигуры двумерных сечений поверхности отклика (рисунок 9), получили экспериментальные уровни факторов, влияющих на срезание кустарниковой растительности роторной косилкой с минимальными затратами энергии. Рисунок показывает, что область оптимума исследуемых факторов находится в следующих пределах: угол заточки режущих кромок ножей $-20-23^{\circ}$; частота вращения ротора $-1600-1650$ обр. мин $^{-1}$; угол расхождения режущих кромок ножей $-65-68^{\circ}$.

Для определения рациональных конструктивно-технологических параметров и режимов работы многороторной косилки с трапециевидными ножами предлагается использовать номограмму (рис. 10), разработанную по результатам теоретических и экспериментальных исследований.

В первом квадранте номограммы представлены линии поступательной скорости перемещения косилки, во втором - линии угла заострения режущих кромок, в третьем - линии частоты вращения ротора, в четвертом - линии угла расхождения режущих кромок. 

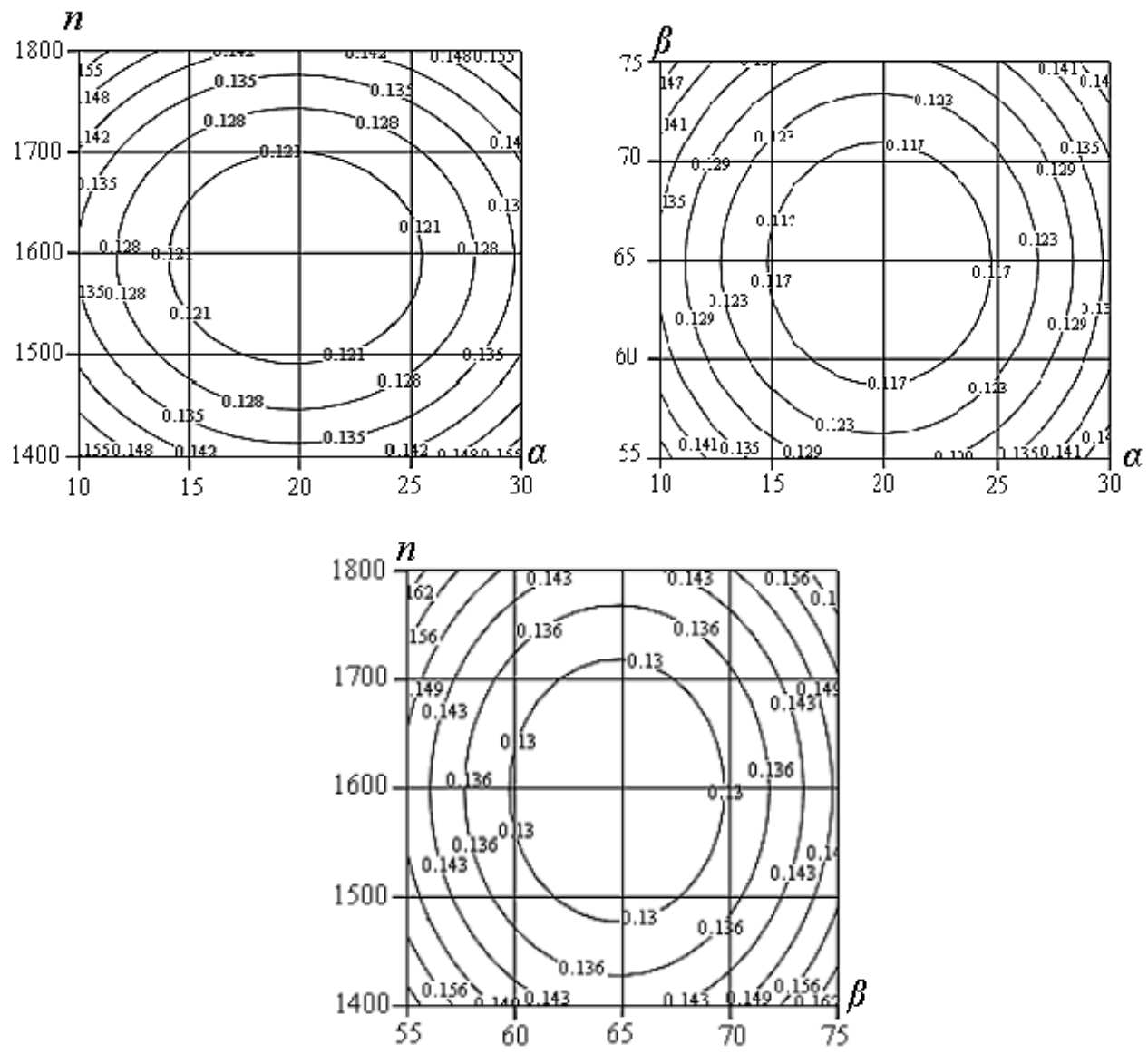

Рисунок 9. Двумерные сечения поверхности отклика по величине крутящего момента для факторов угол заострения режущих кромок, угол расхождения режущих кромок и частота вращения ротора

Приведем пример использования номограммы. Пусть требуется скосить древеснокустарниковую растительность диаметром 45 мм при поступательной скорости перемещения косилки $0,8 \mathrm{~m} \cdot \mathrm{c}^{-1}$, частоте вращения ротора 1600 обр. мин $^{-1}$, угле заострения режущих кромок $25^{\circ}$, угле расхождения режущих кромок $65^{\circ}$. При этих условиях необходимо определить крутящий момент на валу ротора косилки.

Для определения величины крутящего момента на валу ротора в первом квадранте восстанавливаем перпендикуляр из точки $d_{c}=45$ мм до пересечения с линией $v=0,8 \mathrm{~m}^{\cdot} \mathrm{c}^{-1}$ и проводим горизонталь до пересечения с линией $\alpha=25^{\circ}$. Из полученной точки опускаем перпендикуляр до пересечения с линией $n=1600$ обр. мин $^{-1}$ и проводим горизонталь до пересечения с линией $\beta=65^{\circ}$. Опустив из точки 
пересечения перпендикуляр на ось $T$, получим величину крутящего момента на валу ротора $T=155 \mathrm{H} \cdot \mathrm{M}$.

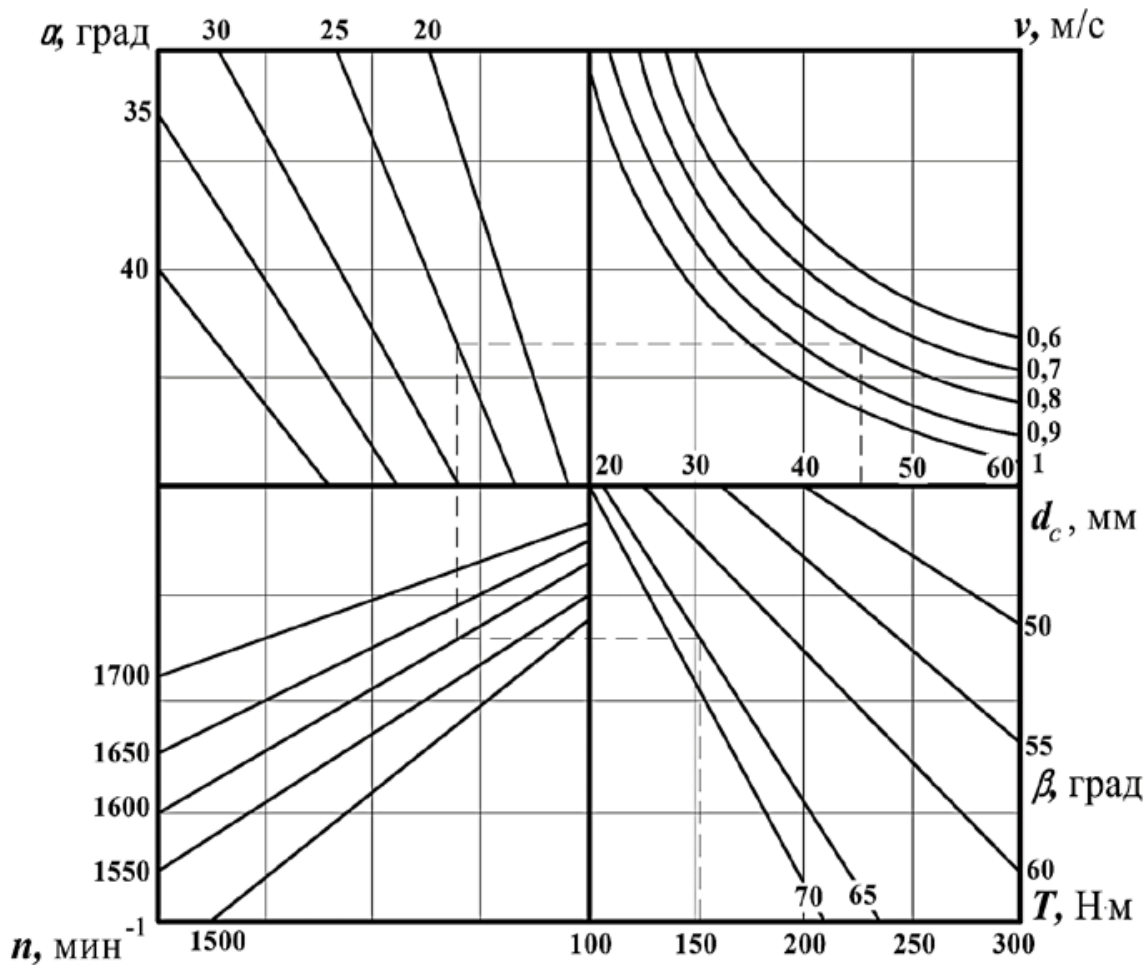

$d_{c}$ - диаметр скашиваемой растительности, мм; $n$ - частота вращения ротора, мин $^{-1} ; \alpha-$ угол заострения режущих кромок ножей, град; $\beta$ - угол расхождения режущих кромок ножей, град; $v$ - поступательная скорость перемещения косилки, м. $c^{-1} ; T$ - крутящий момент на валу ротора, $\mathrm{H} \cdot \mathrm{м}$

Рисунок 10. Номограмма для определения параметров многороторной косилки с трапециевидными ножами

В зависимости от исходных данных подобным образом можно определять и другие параметры, используемые в номограмме, в том числе в ином порядке и с другим перечнем исходных данных.

Применение разработанной номограммы позволяет облегчить задачу по выбору параметров и режимов работы многороторной косилки с трапециевидными ножами.

Во время проведения производственных испытаний производилось скашивание растительности на мелиоративных каналах и придорожных полосах с участками, заросшими сорной травянистой и древесно-кустарниковой растительностью. Среди древесно-кустарниковой растительности преобладали ива и береза, среди сорной травянистой ромашка пахучая, молочай, осока, тростник. 
На косилку устанавливались серийные прямоугольные ножи и ножи усовершенствованной конструкции с углом заострения режущих кромок ножа $-20^{\circ}$ и углом расхождения режущих кромок ножа - 65․ Экспериментальные трапециевидные ножи устанавливались на роторные косилки К-78М и АC-1.

В результате производственных испытаний были определены конструктивнотехнологические показатели косилок К-78М и АC-1, оснащенных трапециевидными ножами. В таблице 1 приведены значения параметров для косилок с серийными ножами, взятые из технических характеристик косилок, и значения для косилок с разработанными ножами, полученные в результате испытаний.

Масса и габаритные размеры косилок при использовании ножей с расходящимися режущими кромками практически не изменились по сравнению с серийными прямоугольными ножами.

Таблица 1.

Конструктивно-технологические показатели косилок, оснащееных трапециевидныли ножами

\begin{tabular}{|c|c|c|c|c|}
\hline \multirow[t]{2}{*}{ Косилка } & \multicolumn{2}{|c|}{ K-78M } & \multicolumn{2}{|c|}{ AC-1 } \\
\hline & $\begin{array}{c}\text { Разработ } \\
\text { анные }\end{array}$ & Серийные & $\begin{array}{c}\text { Разработ } \\
\text { анные }\end{array}$ & Серийные \\
\hline \multicolumn{5}{|c|}{ Конструктивно - технологические параметры } \\
\hline Рабочая скорость, (км·ч $\left.{ }^{-1}\right)$ & 3,4 & 3,4 & 8,2 & 8,2 \\
\hline Рабочая ширина захвата, (м) & 1,59 & 1,58 & 2,09 & 2,08 \\
\hline $\begin{array}{l}\text { Угол расхождения режущих кромок ножей, } \\
\text { (град) }\end{array}$ & 65 & 0 & 65 & 0 \\
\hline Частота вращения роторов, $\left(\right.$ мин $\left.^{-1}\right)$ & 1600 & 1600 & 2000 & 2000 \\
\hline Диаметр ротора по концам ножей, (мм) & 610 & 610 & 610 & 610 \\
\hline Расход топлива, $\left(л \cdot ч^{-1}\right)$ & 6,9 & 6,86 & 6,88 & 6,85 \\
\hline Производительность: & & & & \\
\hline за час основного времени, $\left(\right.$ га·ч $\left.ч^{-1}\right)$ & 0,27 & 0,25 & 1,97 & 1,94 \\
\hline за час эксплуатационного времени, $\left(\right.$ га·ч $\left.{ }^{-1}\right)$ & 0,22 & 0,2 & 1,57 & 1,55 \\
\hline \multicolumn{5}{|c|}{ Условия работы } \\
\hline Коэффициент заложения откосов & $1,1 \ldots 1,2$ & $1,1 \ldots 1,2$ & - & - \\
\hline $\begin{array}{l}\text { Количество стволов } \\
\text { растительности на } 1 \mathrm{~m}^{2} \text {, (шт) }\end{array}$ & 9,7 & 8,2 & 7,9 & 7,9 \\
\hline \multicolumn{5}{|c|}{ Качество работы } \\
\hline $\begin{array}{l}\text { Диаметр скашиваемой растительности, (мм): } \\
\text { травянистой }\end{array}$ & 8,4 & 7,8 & 8,8 & 7,8 \\
\hline кустарниковой & 41,3 & 18,4 & 45,2 & 19,1 \\
\hline Высота срезания, (см) & 7,6 & 7,7 & 7,9 & 8,0 \\
\hline $\begin{array}{l}\text { Количество несрезанных стволов } \\
\text { кустарниковой растительности на } 1 \text { м }^{2}\end{array}$ & 0,6 & 4,6 & 0,7 & 5,1 \\
\hline Состояние среза для кустарника & гладкий & $\begin{array}{l}\text { размочал } \\
\text { енный }\end{array}$ & гладкий & $\begin{array}{c}\text { размочал } \\
\text { енный }\end{array}$ \\
\hline Безопасность выполнения работ & $\begin{array}{c}\text { обеспеч } \\
\text { ена }\end{array}$ & $\begin{array}{c}\text { обеспече } \\
\text { на }\end{array}$ & $\begin{array}{c}\text { обеспеч } \\
\text { ена }\end{array}$ & $\begin{array}{c}\text { обеспече } \\
\text { на }\end{array}$ \\
\hline Эксплуатационная надежность & $\begin{array}{l}\text { достато } \\
\text { чная }\end{array}$ & $\begin{array}{c}\text { достаточ } \\
\text { ная }\end{array}$ & $\begin{array}{l}\text { достато } \\
\text { чная }\end{array}$ & $\begin{array}{c}\text { достаточ } \\
\text { ная }\end{array}$ \\
\hline
\end{tabular}


Cutting of woody...

По результатам проведенных производственных испытаний можно сделать заключение, что трапециевидные ножи обеспечивают качественные показатели процесса скашивания, соответствующие агротехническим требованиям. Причем несколько увеличилась ширина захвата на 1,7\% за счет стабилизации положения ножей во время скашивания, что позволило получить увеличение производительности. По отчетным данным ГПО «Белмелиоводхоз» окашивается только 65\% каналов от их общей протяженности, что подвергает риску зарастания древесно-кустарниковой растительностью оставшиеся 35\%, кроме того по имеющимся данным, в результате несвоевременного проведения ремонтноэксплуатационных работ 18,2 тыс. километров каналов (11,7\% от общего количества) уже заросли древесно-кустарниковой растительностью. Проведенные исследования состояния каналов мелиоративных систем, обслуживаемых ОАО «Горкиводхоз» и ПМК-58 ОАО «Пинскводстрой» показали, что около 6\% от общей протяженности заросли древесно-кустарниковой растительностью. Поэтому производительность дополнительно увеличилась за счет того, что косилка, оснащенная серийными ножами, оставляла нескошенными участки, заросшие древесно-кустарниковой растительностью диаметром более 20 мм, которые приходилось объезжать. Это позволило суммарно повысить производительность на 8\%. Однако в связи с тяжелыми условиями работы, обусловленными скашиванием растительности предельного диаметра, удельный расход топлива увеличился на $0,3 \%$ для косилки К-78М и 0,44\% для $\mathrm{AC}-1$.

При этом диаметр срезаемых стволов древесно-кустарниковой растительности увеличился в 2,2 раза для косилки К-78М и в 2,3 раза для АС-1. Несколько снизилась высота среза. Кроме того, применение трапециевидных ножей позволило значительно снизить количество несрезанных стволов кустарниковой растительности, повысить качество среза. Срезанные остатки древеснокустарниковой растительности разлетались на расстояние не более 10 м, что свидетельствует об обеспечении безопасности выполнения работ. При проведении испытаний погнутость ножей не отмечалась, замеры диаметра отверстий в дисках и ножах показали незначительную величину износа, что подтверждает эксплуатационную надежность.

\section{Заключение}

1. В результате теоретических и экспериментальных исследований установлено, что рациональными геометрическими параметрами режущей кромки ножа роторной косилки при срезании древесно-кустарниковой растительности пород ива, береза, ольха и осина на мелиоративных объектах являются угол заострения режущей кромки $20^{\circ}$ и верхний либо двухсторонний вариант заострения режущих кромок ножа (Шаршунов и др., 2011).

2. На основании разработанной расчетной схемы, учитывающей все значимые усилия, действующие на нож в процессе срезания стеблей древеснокустарниковой растительности, установлены основные закономерности ее скашивания. Получены аналитические выражения для определения минимально необходимой скорости ножа для срезания ствола растительности с учетом сил 
сопротивления его срезанию и отгибу при ударном воздействии, угла отклонения ножа от радиального положения при контакте со стеблем, реакции в шарнире «нож - болт крепления», устанавливающая ее зависимость от параметров ножа и ротора, расстояния от центра болта крепления ножа до точки контакта ножа со стеблем, при котором реакция в шарнире будет минимальной, скорости рабочего передвижения косилки, при которой будет обеспечена наименьшая нагрузка на болт и соответственно достигнута наибольшая эффективность скашивания растительности. Теоретически и экспериментально обосновано рациональное значение угла расхождения режущих кромок, составляющее 65-70

3. Получена математическая модель процесса скашивания древесно-кустарниковой растительности многороторной косилкой с трапециевидными ножами. В результате решения задачи оптимизации полученной модели на ПЭВМ в Мicrosoft Excel были получены оптимальные значения исследуемых факторов: частота вращения ротора косилки 1600 обр. мин $^{-1}$, угол заострения режущих кромок ножей $20^{\circ}$, угол расхождения режущих кромок $65^{\circ}$, при которых обеспечивается минимальная величина крутящего момента на валу ротора косилки, равная 110,8 Н м (Шаршунов и др. 2012).

4. Результаты производственных испытаний показали, что применение косилки с трапециевидными ножами позволяет увеличить диаметр скашиваемой растительности в 2,2-2,3 раза, значительно снизить количество несрезанных стволов древесно-кустарниковой растительности, повысить качество среза при обеспечении безопасности выполнения работ и сохранении эксплуатационной надежности (Шаршунов и др. 2013б).

5. Разработана номограмма, позволяющая с учетом известных исходных характеристик стеблестоя древесно-кустарниковой растительности подобрать параметры ножей и режимы работы косилки для скашивания растительности на мелиоративных объектах.

\section{Литература}

Бохан, Н.И., Дмитриев, А.М, Нагорский, И.С. (1986). Планирование эксперимента в исследованиях по механизачии и автоматизации сельскохозяйственного производства. Горки, 79.

Кондратьев, В.Н. (2007). Особенности конструкций отечественных и зарубежных косилок для ухода за мелиоративными системами. Мелиорация переувлажнённых земель. №1, 31-39.

Корнилович, Р.А. (2007). Совершенствование режущего аппарата ротационной косилки. диссертация кандидата технических наук: 05.20.01. М, 156.

Мажугин, Е.И. (2010). Машины для эксплуатации мелиоративных и водохозяйственных объектов. Пособие. Горки: Белорусская государственная сельскохозяйственная академия, 333.

Мажугин, Е.И., Рубец, С.Г. (2011). Секторный нож роторной косилки. Конструирование, использование и надежность машин сельскохозяйственного назначения: сборник научных работ междунар. Науч.- техн. конф., Брянск, 22-24 февраля 2011 г. / ФГОУ ВПО Брянск. гос. с-х. академия; редкол.: А.А. Тюрева [и др.]. - Брянск, 31-35.

Мартынов, В.М. (2009). Геометрия ножа ротационного режущего аппарата. Tракторы и сельхозмашины. №3, 34-36. 
Cutting of woody...

Мельников, С.В., Алешкин, В.Р., Рощин, П.М. (1976). Планирование эксперимента в исследованиях сельскохозяйственных процессов. Л.: Колос, 168.

Новиков, Ю.Ф. (1957). Теория и расчет ротационного режущего аппарата с рубящими рабочими органами. Сельхозмашина. №8, 3-8.

Резник, Н.Е. (1975). Теория резания лезвием и основы расчета режущих аппаратов. М.: Машиностроение, 311.

Титов, В. Н., Гуцанович, К.А. (2009). Определение характеристики древесно-кустарниковой растительности на каналах мелиоративных систем. Мелиоращия. №1(61), 222-228.

Шаршунов, В.А., Мажугин, Е.И., Рубец, С.Г. (2009). Нож роторной косилки: пат. 5809 Респ. Беларусь, МПК A 01D 34/01; заявитель Белорус. гос. с-х. академия. № u 20090403; заявл. 19. 05. 09; опубл. 30. 12. 09. Афіцыйны бюл. Нац. цэнтр інтэлектуал. уласнасці. № 6, 148.

Шаршунов, В.А., Мажугин, Е.И., Рубец, С.Г. (2011). Обоснование геометрических параметров режущей кромки ножа роторной косилки, используемой на мелиоративных объектах. Вестник Национальной академии наук Беларуси. Серия агротехнические науки. № 3, 102107.

Шаршунов, В.А. Мажугин, Е.И., Рубец, С.Г. (2012). Результаты экспериментальных исследований усовершенствованных ножей роторной косилки при срезании кустарниковой растительности. Вестник Белорусской сельскохозяйственной академии. Механизация $u$ сельскохозяйственное машиностроение. № 2, 147-153.

Шаршунов, В.А., Мажугин, Е.И., Рубец, С.Г. (2013). Теоретический анализ влияния угла расхождения режущих кромок ножа роторной косилки на его параметры. Вестник Белорусской сельскохозяйственной академии. Механизаиия и сельскохозяйственное матиностроение. № 1, 98-104.

Шаршунов, В.А. Мажугин, Е.И., Рубец, С.Г. (2013). Производственные испытания роторной косилки, оснащенной ножами $\mathrm{c}$ расходящимися режущими кромками. Вестник Белорусской сельскохозяйственной академии. Механизация и сельскохозяйственное машиностроение. № 1, 114-119.

Фомин, В.И. (1963). Обоснование параметров косилочного режущего аппарата сегментнодискового типа. Автореферат диссертации кандидата технических наук: 05.20.01. Ростов н/Д., 22.

\section{WIELOTARCZOWA KOSIARKA Z TRAPEZOWYMI NOŻAMI DO KOSZENIA ROŚLINNOŚCI NA ROWACH MELIORACYJNYCH}

Streszczenie. Celem pracy było opracowanie technologii koszenia roślinności na glebach odłogowanych i obiektach melioracyjnych, a także zwiększenie efektywności pracy wielobębnowej kosiarki z nożami trapezowymi. Rozważania teoretyczne prowadzono na bazie praw mechaniki, natomiast doświadczenia z wykorzystaniem specjalistycznej aparatury oraz metod obliczeniowych. Określono między innymi zależności analityczne na kąt odchylenia noża od położenia radialnego, reakcję w przegubie (nóż-sworzeń) w zależności od parametrów geometryczno-kinematycznych. Opracowano metodykę wyznaczania podstawowych parametrów pracy nożowego zespołu tnącego. Sporządzono nomogram wyznaczania podstawowych wartości parametrów eksploatacyjnych oparty na teoretyczno-eksperymentalnych zależnościach. W pierwszym kwadracie monogramu są linie prędkości postępowej kosiarki, w drugim - linie kąta zaostrzenia tnących ostrzy, w trzecim linie prędkości kątowej bębna, w czwartym - linie kąta rozwarcia tnących ostrzy.

Słowa kluczowe: wielotarczowa kosiarka, roślinność trawiasto-krzewiasta, noże trapezowe, obiekty melioracyjne, koszenie, efektywność 